\title{
Effect of Preheating Temperature on ECAP Formability of AC4CH Aluminum Casting Alloy
}

\author{
Yoshihiro Nakayama $^{1}$ and Tetsuya Miyazaki ${ }^{2}$ \\ ${ }^{1}$ University of Yamanashi, Interdisciplinary Graduate School of Medicine and Engineering, \\ Science Department of Research, Kofu 400-8511, Japan \\ ${ }^{2}$ University of Yamanashi, Interdisciplinary Graduate School of Medicine and Engineering, \\ Science Department of Education, Kofu 400-8511, Japan
}

Effects of preheating treatment on the microstructural features and the ECAP formability at room temperature were investigated for an $\mathrm{AC} 4 \mathrm{CH}$ aluminum alloy. The preheating treatment at the temperature range from 260 to $560^{\circ} \mathrm{C}$ improved the ECAP formability at room temperature, especially at around $350^{\circ} \mathrm{C}$ the occurrence of cracks was inhibited effectively. When the preheating treatment was carried out at $410^{\circ} \mathrm{C}$ or less the hardness of primary $\alpha$-Al decreased with rise in preheating temperature, while the increase of the hardness was observed for the test pieces preheated at above $470^{\circ} \mathrm{C}$. The observation on the eutectic Si particles showed that the mean cross-sectional area and the spherical coefficient were constant at the preheating temperatures below $410^{\circ} \mathrm{C}$ but increased clearly at $470^{\circ} \mathrm{C}$ and higher. In addition to the above, when the hardness of the primary $\alpha$-Al reached to a specified value due to a strain hardening by the repetitive ECAP press, the cracks occurred in the test piece and the ECAP process became impossible. These experimental results implied that the hardness of the primary $\alpha$-Al gave a useful indication for the ECAP formability at room temperature. Cracks at the rear section of the test piece initiated on the inner side of ECAP channel angle and propagated preferentially along the solidification cell regions, that is, not only at the interface between aluminum matrix and eutectic $\mathrm{Si}$ particles but also at the transcrystalline cracking of eutectic Si particles. [doi:10.2320/matertrans.L-M2010805]

(Received November 28, 2009; Accepted January 22, 2010; Published March 25, 2010)

Keywords: sever plastic deformation, AC4CH aluminum casting alloy, equal-channel angular pressing, preheating temperature, primary $\alpha$-aluminum, eutectic silicon particle, hardness

\section{Introduction}

Al-Si eutectic alloys are in wide use in the automobile industry because of their good amenability to casting, high strength and excellent wear resistance and so on. However, the Al-Si casting alloys exhibit a poor ductility and toughness due to their microstructures consisting of the aluminum dendrites, the eutectic Si particles and the casting defects such as the shrinkage pores. Various modification and heattreatment techniques have been developed to improve the ductility of the Al-Si casting alloy. ${ }^{1)}$ The first category of research is aimed at modifying the morphology of eutectic $\mathrm{Si}$ particles. Eutectic modifiers such as sodium and strontium are widely used to spheroidize Si particles. In addition to the above, solution heat treatment, which conducted at high temperature around $530^{\circ} \mathrm{C}$ for long time, is used to modify the morphology of $\mathrm{Si}$ particles. The spheroidization and coarsening of $\mathrm{Si}$ particles is achieved by the solution heat treatment and the ductility of the casting alloy is modified. The second category of research deals with the refinement and redistribution of the eutectic Si particles and the primary $\alpha$-Al by applying the semi-solid casting process, the squeezed casting process and the casting-forging process and so on. Recently, Sever Plastic Deformation processes such as HighPressure Torsion, Accumulative Roll Bonding and EqualChannel Angular Pressing are used to refine and redistribute the eutectic $\mathrm{Si}$ particles and the primary $\alpha-\mathrm{Al} .^{2-7)} \mathrm{SPD}$ process results in a marked refinement and redistribution mentioned above, gives a homogeneous distribution of $\mathrm{Si}$ particles in the aluminum matrix, and nearly eliminates the shrinkage pores. These microstructural improvements lead to a good ductility and toughness in the Al-Si casting alloys. Aibin Ma et al. investigated the effects of ECAP process on the tensile properties and the impact toughness of the Al-Si casting alloys and pointed out that the ductility and the impact toughness were significantly improved due to the refinements of the primary $\alpha-\mathrm{Al}$ and the homogeneous distribution of the eutectic $\mathrm{Si}$ particles during ECAP processing. ${ }^{8-11)}$ Since the ECAP process conducted by Aibin Ma et al. was carried out at elevated temperatures (300 to $400^{\circ} \mathrm{C}$ ) in order to precede a formability of the test piece, a die equipped with heater and more complicated operations were required. In addition to the above, ECAP process at high temperature brought about a reduction in the accumulation efficiency of strain. To overcome the drawbacks related to ECAP process at elevated temperatures, it is desirable to lower the processing temperature of ECAP pass. In order to realize this objective, investigation of the microstructure, which is suitable for ECAP process at room temperature, is of great importance. On the other hand, the microstructure preferred to ECAP process makes it easy to perform a local improvement of mechanical properties of casting products by employing other SPD technique such as Friction Stir Processing. The objective of this work is as follows; firstly, effects of preheating temperature on the ECAP formability at room temperature are examined experimentally for the AC4CH casting alloy. Secondly, changes in microstructural features with the preheating temperature are evaluated quantitatively. And finally, relationships between the microstructural features and the ECAP formability at room temperature are discussed.

\section{Experimental Details}

Test pieces having the rectangular shape $(40 \mathrm{~mm} \times$ $15 \mathrm{~mm} \times 5 \mathrm{~mm}$ ) for the ECAP process were prepared from the $\mathrm{AC} 4 \mathrm{CH}$ aluminum alloy ingot. The chemical composition (mass\%) of the applied ingot was as follows; Si7.16, 


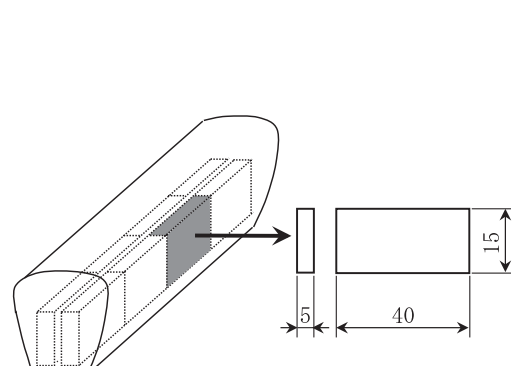

(a)

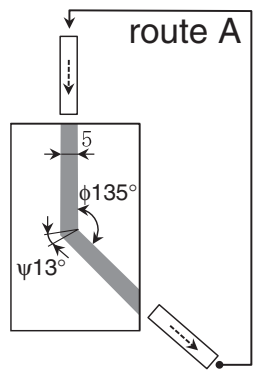

(b)
Fig. 1 Schematic illustrations showing test piece shape and cut-off position from ingot (a) and die configuration and route of ECAP process (b).

Mg0.31, Fe0.09, Zn0.02, Ti0.11, Sr72 (ppm), and balance Al. The melt at $700^{\circ} \mathrm{C}$ was poured into a JIS type permanent mould held at $150^{\circ} \mathrm{C}$ under atmospheric pressure. Shape and cut-off position of the test piece were shown in Fig. 1(a). The test pieces were preheated for $30 \mathrm{~min}$ and subsequently quenched into iced-water $\left(0^{\circ} \mathrm{C}\right)$. The maximum temperature of the preheating treatment was selected as $575^{\circ} \mathrm{C}$ on the basis of the preliminary examinations on the solidus temperature of the applied $\mathrm{AC} 4 \mathrm{CH}$ aluminum alloy ingots. After preheating treatment, the test pieces were naturally aged for $48 \mathrm{~h}$ and then subjected to ECAP process at room temperature using a die having a channel angle $\phi$ of $135^{\circ}\left(\psi=13^{\circ}\right)$ shown in Fig. 1(b). The processing route of the present study is that of Route A according to the classification given by Horita et al. ${ }^{12)}$ Grease containing fine $\mathrm{MoS}_{2}$ particles was used to decrease the friction between the test piece and the die. The equivalent strain induced by 1-pass in ECAP process was estimated as about 0.47 from the following eq. (1). ${ }^{12)}$

$$
\varepsilon_{N}=\frac{N}{\sqrt{3}}\left[2 \cot \left(\frac{\phi}{2}+\frac{\psi}{2}\right)+\psi \operatorname{cosec}\left(\frac{\phi}{2}+\frac{\psi}{2}\right)\right]
$$

Here, $N$ is the number of ECAP pass.

Differential scanning calorimetry and Vickers microhardness measurement were also made after natural aging for $48 \mathrm{~h}$. A quantitative measurement using an image analyzer was also carried out in order to estimate changes in the size and the morphology of eutectic Si particles with the preheating temperature.

\section{Results and Discussion}

\subsection{Effect of preheating temperature on ECAP form- ability}

Table 1 shows the effect of preheating temperature on the ECAP formability and optical micrographs of the test pieces after ECAP process are shown in Fig. 2. The marks in Table 1 indicate the occurring state of a crack in the test piece; double circle mark "()" means no cracks, triangle mark " $\triangle$ " reveals that many cracks occur all over the inner side surface of ECAP channel angle, and single circle mark " $\bigcirc$ " describes the state that a crack occurs only in the front section of the test piece. As seen in Table 1 and Fig. 2, when the preheating treatment is carried out at 200,230 , or $575^{\circ} \mathrm{C}$, many cracks occur all over the inner side surface in the test piece even at 1st-pass in the ECAP process. A similar
Table 1 Effect of preheating temperature on ECAP formability.

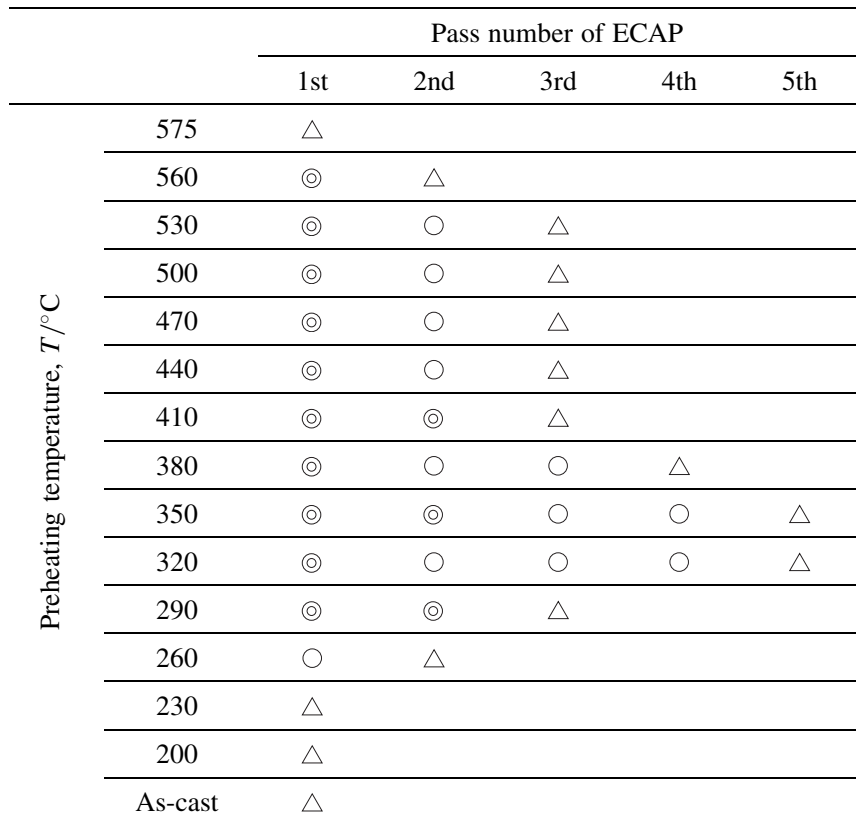

○): no cracks, $\bigcirc$ : a crack in front section, $\triangle$ : many cracks

tendency on the occurring state of cracks is observed in the As-cast specimen. In contrast, ECAP process becomes feasible when the preheating treatment is conducted at the temperature range from 260 to $560^{\circ} \mathrm{C}$. When the specimen is preheated at $350^{\circ} \mathrm{C}$, the cracks do not occur until 2nd-pass. Generation of a crack in the front section of test piece is found at 3rd- and 4th-pass, and when the ECAP process reaches at 5th-pass the cracks occur simultaneously not only at the front section but also at the rear section.

The cause of first crack occurrence at the front section is considered to be a lack of the axial compressive stress in press direction during the ECAP process, suggesting that the bending deformation instead of shearing deformation is regarded as a dominant factor governing the plastic deformation at that section. In order to investigate the effects of axial compressive stress on the occurring behaviors of cracks, variations in the cylinder pressure during the ECAP process are measured. Figure 3 shows the plots of cylinder pressure, which corresponds to the axial compressive stress acting on the test piece, against the displacement of punch. In Fig. 3, cylinder pressures obtained by the different ECAP techniques are plotted together as a function of the punch displacement. One of which is the method in which a test piece is pressed alone and re-inserted for the next pass (Individual Press). The other is the method in which two test pieces are pressed continuously (Continuous Press), that is, whenever the following test piece is pressed, the preceding one lies in front of it. For convenience these methods are called as INP and COP, hereafter. Cylinders pressures increase gradually and then saturate with proceed in the ECAP press. Comparing with COP, lower value of cylinder pressure is measured for INP, particularly in the early stage of ECAP press (punch displacement $L<20 \mathrm{~mm}$ ). Therefore, it is considered that this reduction of cylinder pressure in INP is responsible for the bending deformation resulting in the crack occurrence at the front section of test piece. Figure 4 shows examples of 


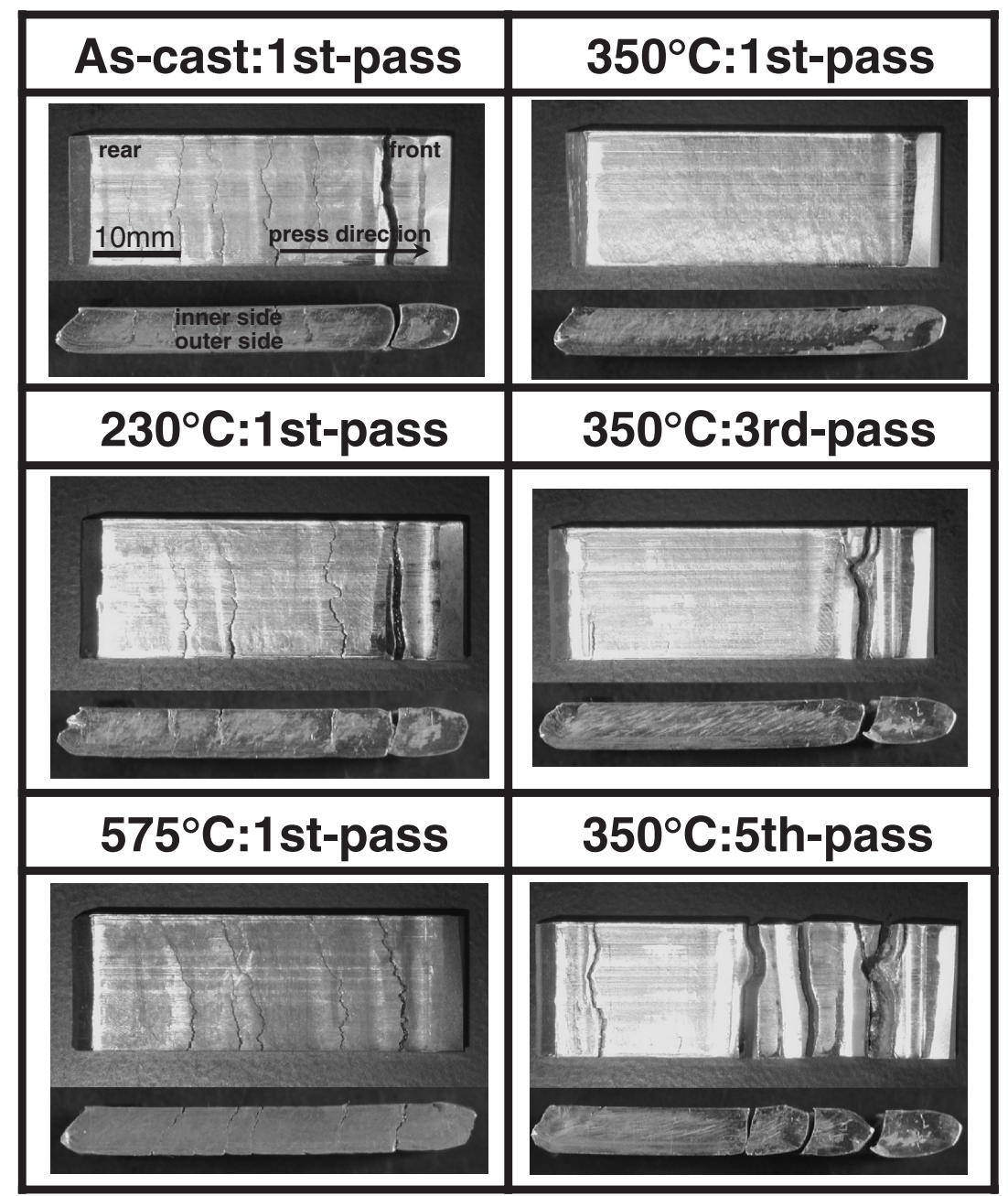

Fig. 2 Optical micrographs of test pieces. Preheating treatment was carried out at temperature range from 200 to $575^{\circ} \mathrm{C}$ for 30 min before ECAP process.

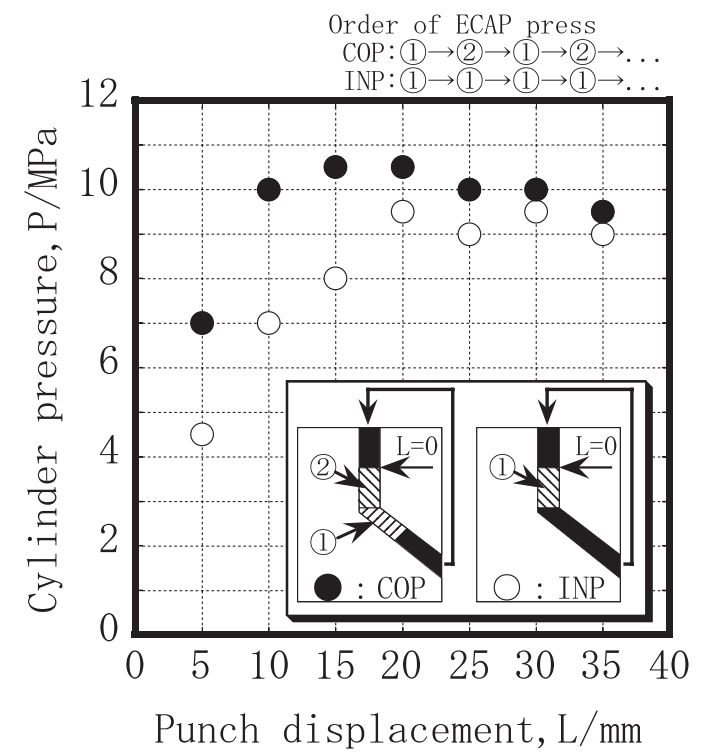

Fig. 3 Plots of cylinder pressure against punch displacement. In INP (individual press) technique a test piece was pressed repetitively, while two test pieces were pressed continuously in COP (continuous press) technique. Whenever following test piece was pressed in COP technique, preceding test piece lay in front of it. the test pieces ECAP processed by COP. These test pieces are preheated at $350^{\circ} \mathrm{C}$ and then ECAP processed by COP for up to 5th-pass. The cracks do not occur in the front section because of increase in the axial compressive stress, in contrast, many cracks occur when the test piece is ECAP processed by INP technique (Fig. 2). It can be concluded by the findings mentioned above that an increase of the axial compressive stress inhibits the occurrence of cracks. S. B. Kang et al. had pointed out that the test piece was safe from tensile mode cracking by the hydrostatic compressive pressure. ${ }^{13)}$ Unless otherwise noted, following data shows the results of the test pieces ECAP processed by INP technique.

\subsection{Effect of preheating temperature on microstructural features}

Microstructural features which may affect the ECAP formability are dendrite arm spacing, hardness of the aluminum matrix, morphology of the eutectic Si particles, casting defects and so on. Since the preheating treatment has a great influence on the hardness of the aluminum matrix and the size and the morphology of the eutectic Si particles, changes in these microstructural features with the preheating temperature are investigated in detail. 


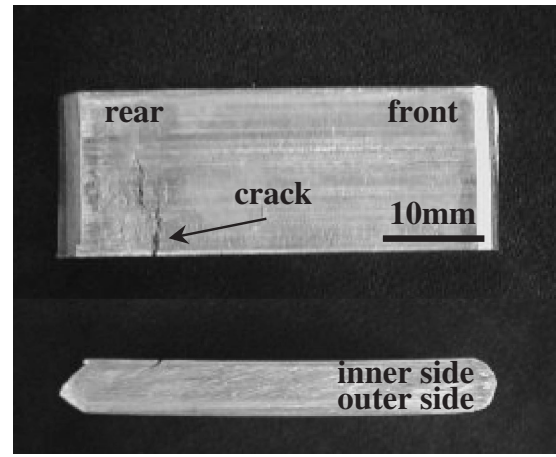

Specimen A

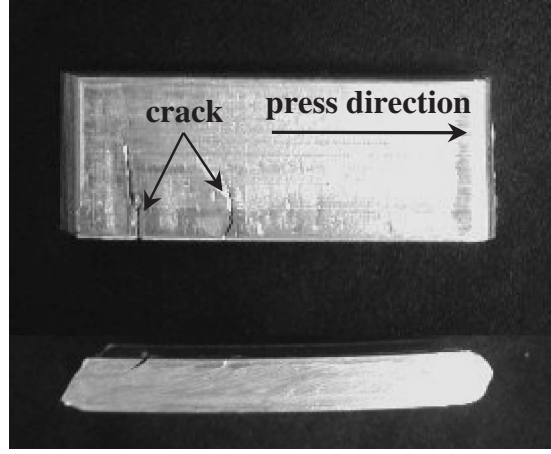

Specimen B

Fig. 4 Optical micrographs showing effect of axial stress on ECAP formability. Specimen A and B were ECAP processed for up to 5th-pass by COP technique after preheating treatment at $350^{\circ} \mathrm{C}$.

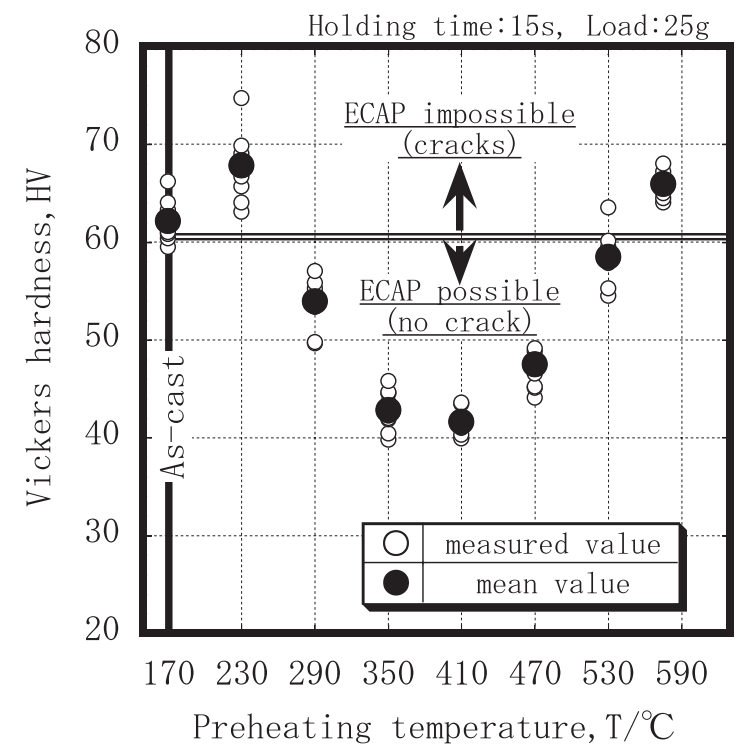

Fig. 5 Effect of preheating temperature on Vickers hardness. Vickers hardness measurement on primary $\alpha$-Al was conducted under indentation load of $25 \mathrm{~g}$. In this figure, mean hardness value of primary $\alpha$-Al was shown together with each measured value.

First of all, changes in Vickers hardness of the primary $\alpha$ $\mathrm{Al}$ with the preheating temperature is examined. The reason why Vickers hardness of the primary $\alpha$-Al was measured is that microstructural feature, which may tend to vary by preheating treatment and ECAP process, is not the hardness of the eutectic Si particles, but that of the primary $\alpha$-Al. Light load $25 \mathrm{~g}$ is selected as an indentation load in order to measure the hardness of primary $\alpha$-Al independently. Plots of Vickers micro-hardness against the preheating temperature are shown in Fig. 5. When the preheating treatment is conducted at below $410^{\circ} \mathrm{C}$, the hardness of primary $\alpha$-Al decreases with rise in preheating temperature. Growth and coarsening of the precipitates such as $\beta^{\prime}$-phase and $\mathrm{Mg}_{2} \mathrm{Si}$ during the preheating treatment may lead to this decrease of the hardness. ${ }^{14)}$ In contrast, at preheating temperatures above $470^{\circ} \mathrm{C}$, the hardness increases with rise in temperature, which may be arising from the solid-solution hardening by such elements as silicon and magnesium.

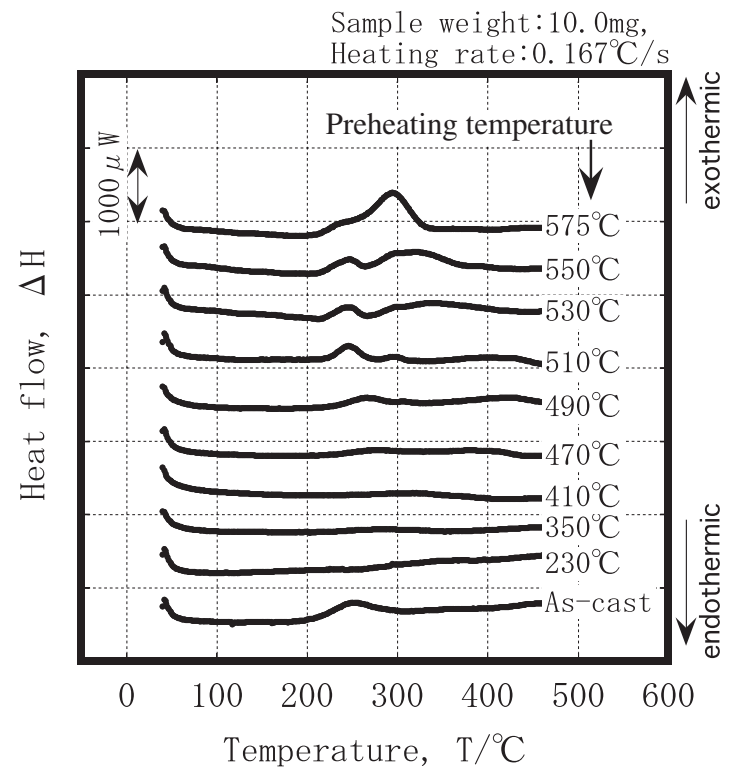

Fig. 6 Effect of preheating temperature on heat flow curves.

Differential scanning calorimetry analysis is also carried out to estimate amounts of solid solutions, and measured heat flow curves are shown in Fig. 6. When the preheating treatment is carried out at above $470^{\circ} \mathrm{C}$, heat flow curves show an exothermic heat reaction at the temperature range from 220 to $350^{\circ} \mathrm{C}$, indicating that the amounts of this exothermic heat reaction increase with rise in preheating temperature. Because precipitation of the precipitates such as $\beta^{\prime \prime}$ - and $\beta^{\prime}$-phase during the heating process brings about this exothermic heat reaction, ${ }^{14)}$ so the specimens preheated at above $470^{\circ} \mathrm{C}$ may be strengthened by solid-solution hardening as preheated condition. Consequently, these specimens may exhibit precipitation hardening behaviors when the artificial aging treatment is conducted. On the other hand, since there is no heat reaction for the specimens preheated at $410^{\circ} \mathrm{C}$ and below it is expected that the precipitation may proceed during the preheating process.

Based on the experimental results on the hardness (Fig. 5) and the heat flow curves (Fig. 6), it is concluded that when the preheating treatment is carried out at $410^{\circ} \mathrm{C}$ and below the decrease in the hardness of primary $\alpha-\mathrm{Al}$ is resulted from 


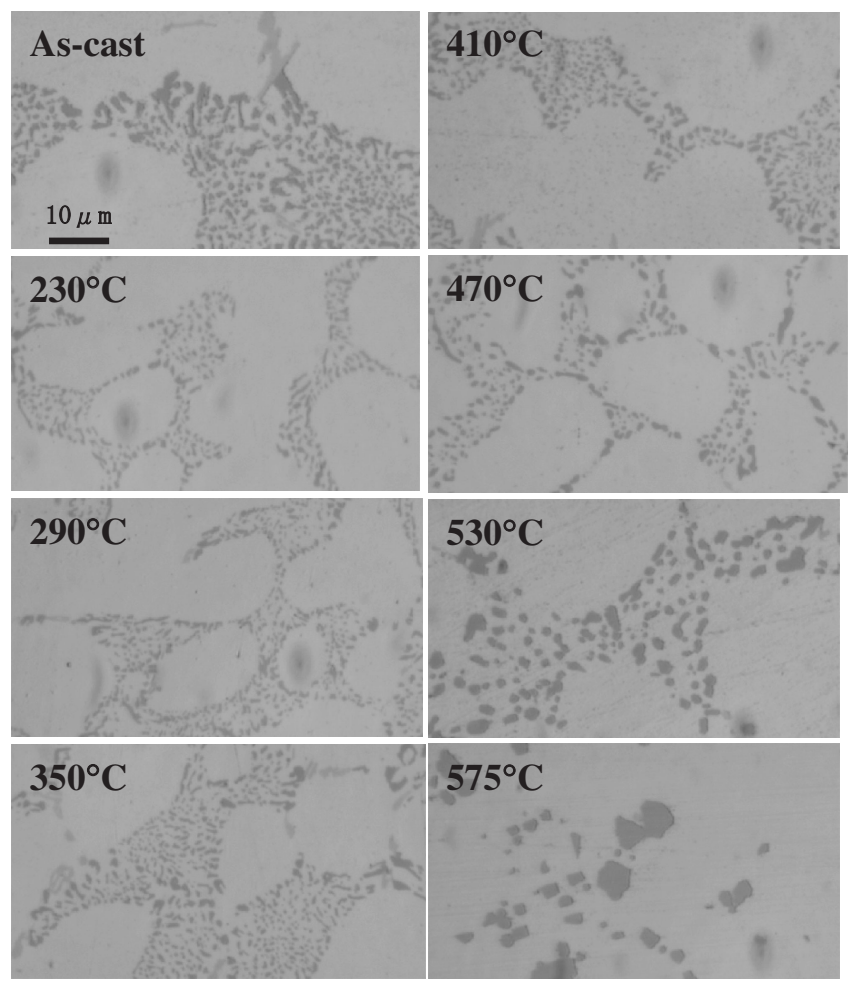

Fig. 7 Optical micrographs showing effect of preheating temperature on microstructures.

coarsening of the precipitates, while at $470^{\circ} \mathrm{C}$ and above the hardness increases due to the solid-solution hardening.

Figure 7 shows the microstructure of the test pieces with or without preheating treatment. Microstructure of As-cast specimen exhibits ordinary structure consisting of primary $\alpha$-Al and modified eutectic Si particles. When the preheating treatment is carried out at $410^{\circ} \mathrm{C}$ and below, there are no changes in the cross-sectional area and the morphology of eutectic Si particles. In contrast to that, the coarsening and spheroidization of eutectic Si particles are clearly observed for the test pieces preheated at above $470^{\circ} \mathrm{C}$. Quantitative data on eutectic Si particles is summarized in Fig. 8. In Fig. 8, spherical coefficient gives the ratio of cross-sectional area of measuring Si particle to that of an ideal particle. The ideal particle has a perfectly round shape, that is, its radius is equivalent to the long axis of the measuring $\mathrm{Si}$ particle. For the test pieces preheated at $410^{\circ} \mathrm{C}$ and below there are no noticeable changes in the mean cross-sectional area and the spherical coefficient. However, when the preheating treatment is carried out at $470^{\circ} \mathrm{C}$ and above, the microstructures after preheating treatment are characterized by significant coarsened and fairly rounded eutectic Si particles.

The results mentioned above (Table 1, Fig. 5 and Fig. 8) imply that the decrease of the hardness of the primary $\alpha-\mathrm{Al}$ improves the formability of ECAP process, regardless of the mean cross-sectional area and the morphology of eutectic $\mathrm{Si}$ particles.

\subsection{Effect of ECAP process on microstructural features}

Several ECAP processes are interrupted in order to investigate effects of ECAP pass on the microstructural features such as the hardness of primary $\alpha$-Al, the redis-

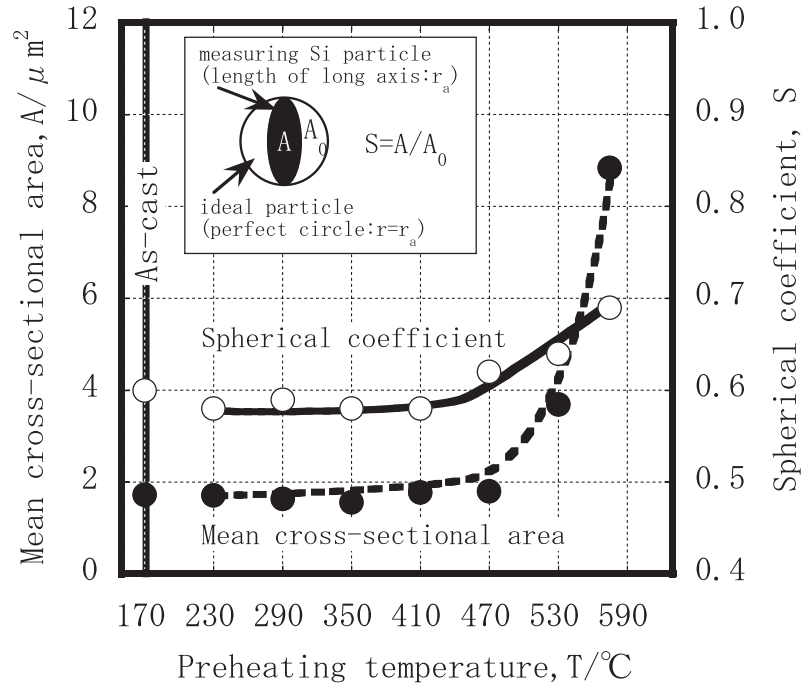

Fig. 8 Effect of preheating temperature on mean cross-sectional area and spherical coefficient of eutectic Si particles.

tribution of eutectic Si particles, and the initiation behaviors of cracks. Figure 9 shows the optical micrographs of the test piece preheated at $350^{\circ} \mathrm{C}$ and then ECAP processed. ECAP process brakes down the eutectic structures in network form, that is, both the primary $\alpha$-Al dendrite and the inter-dendritic eutectic Si particles elongate together along the shearing direction. As a result, lamellar structures consisting of the primary $\alpha-\mathrm{Al}$ and the eutectic Si particles become thin with proceeding of ECAP process, which is the ordinary microstructural features observed for the test pieces ECAP processed through route A. ${ }^{12)}$

Changes in Vickers hardness with the number of ECAP pass are shown in Fig. 10 for the test pieces preheated at $350^{\circ} \mathrm{C}$. Hardness of the primary $\alpha-\mathrm{Al}$, which may tend to vary by ECAP process, is measured at the rear section of the test piece where the adequate axial compressive stress is acting on. Hardness of the primary $\alpha-\mathrm{Al}$ increases monotonously with proceeding of ECAP pass and when the hardness exceeds $60 \mathrm{HV}$ cracks occur at the rear section. As shown in Fig. 5, the preheating treatment resulting in the decrease in hardness to less than 60HV improves the ECAP formability. On the basis of these experimental facts, the hardness value of the primary $\alpha$-Al, $60 \mathrm{HV}$, seems to give a guide whether the ECAP process becomes feasible or not.

Observation of the microstructure is carried out at the rear section of the test piece in order to investigate the initiation and propagation behaviors of cracks. Crack growth path is shown in Fig. 11(a)-(c) for the test pieces after ECAP process. Regardless the preheating treatment and/or the number of ECAP pass cracks propagate from the inner side of channel angle to the outer side, showing preferential propagation of the cracks along the solidification cell regions in which the eutectic $\mathrm{Si}$ particles are segregated. High magnification pictures in the solidification cell regions indicate clearly that the cracks propagate not only at the interface between aluminum matrix and eutectic Si particles but also at the transcrystalline cracking of eutectic Si particles. These results mean that the deformation state in the solidification cell regions, that is, the cracking character- 

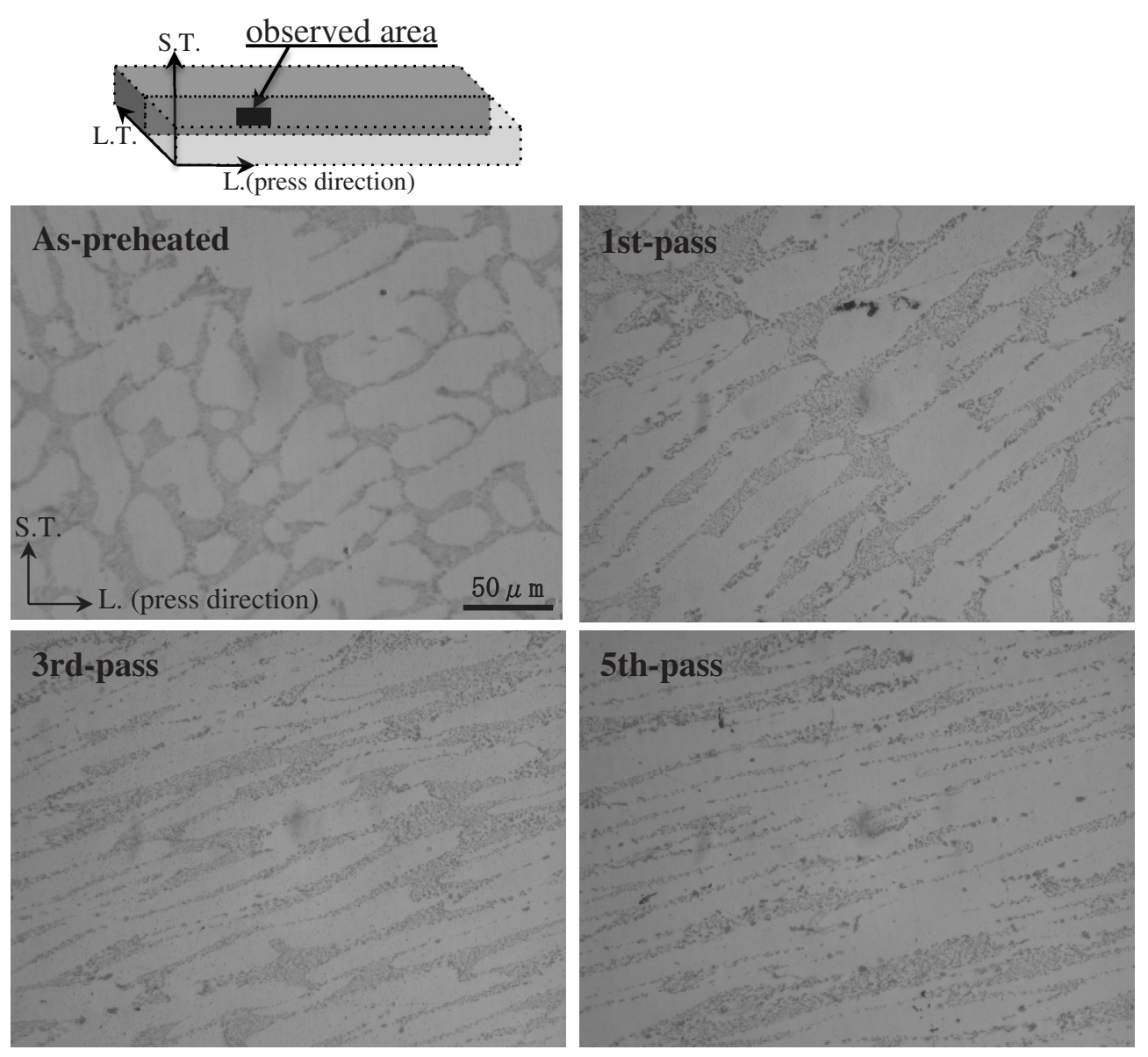

Fig. 9 Optical micrographs showing effect of ECAP pass on microstructures. Before ECAP process specimens were preheated at $350^{\circ} \mathrm{C}$ for $30 \mathrm{~min}$.

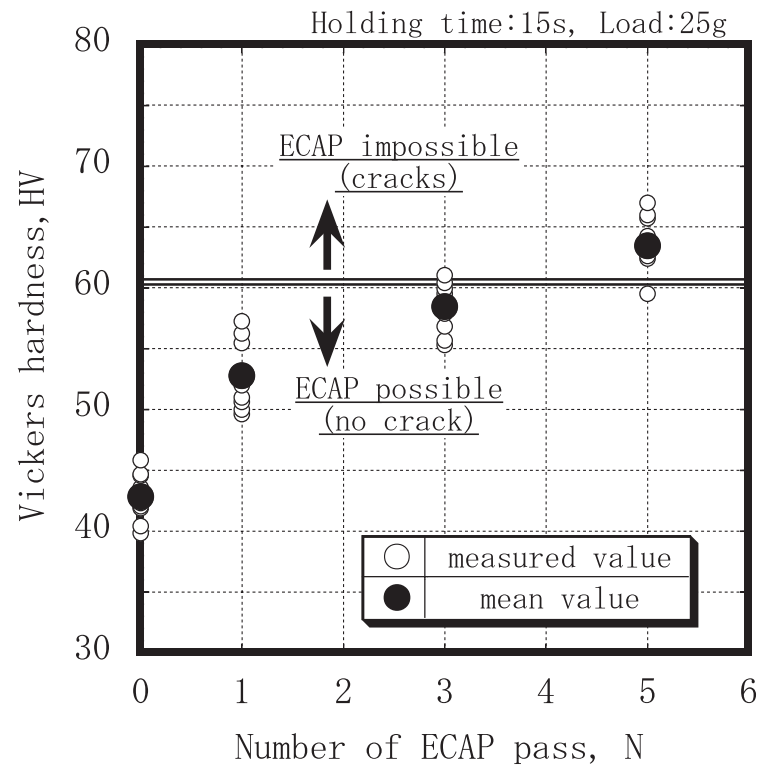

Fig. 10 Plots of Vickers hardness against ECAP pass number. Measurement of Vickers hardness on primary $\alpha$-Al was carried out at rear section of test piece under indentation load of $25 \mathrm{~g}$. Before ECAP process, preheating treatment was conducted at $350^{\circ} \mathrm{C}$ for $30 \mathrm{~min}$.

istic of the eutectic Si particles and the deformation behavior of the aluminum matrix surrounding the Si particles, play an important role in ECAP formability.
Since the hardness shown in Fig. 10 is measured not in the aluminum matrix surrounding the $\mathrm{Si}$ particles but in the primary $\alpha-\mathrm{Al}$, the cracking behaviors in the solidification cell regions is of less concern in this hardness. Test pieces are strain hardened gradually by each ECAP pass. Hardness increase by strain hardening may be high in the aluminum matrix surrounding the eutectic Si particles as compared with that in the primary $\alpha$-Al. When the hardness of the primary $\alpha$ $\mathrm{Al}$ reaches to about $60 \mathrm{HV}$, there are many damages, which is resulted from the interfacial cracking between aluminum matrix and eutectic $\mathrm{Si}$ particles and the transcrystalline cracking of eutectic Si particles, in the solidification cell regions. This may be the reason why there is a relationship between the ECAP formability and the hardness of the primary $\alpha$-Al. In a subsequent paper the relationship between a heterogeneous deformation and cracking characteristics will be investigated in detail on the basis of hardness measurements both in the aluminum matrix surrounding the eutectic Si particles and in the primary $\alpha$-Al.

\section{Summary}

Effects of preheating temperature on the microstructural features and the ECAP formability at room temperature were examined for $\mathrm{AC} 4 \mathrm{CH}$ aluminum casting alloys. When the preheating treatment was carried out at around $350^{\circ} \mathrm{C}$ ECAP formability was significantly improved, while cracks occur- 


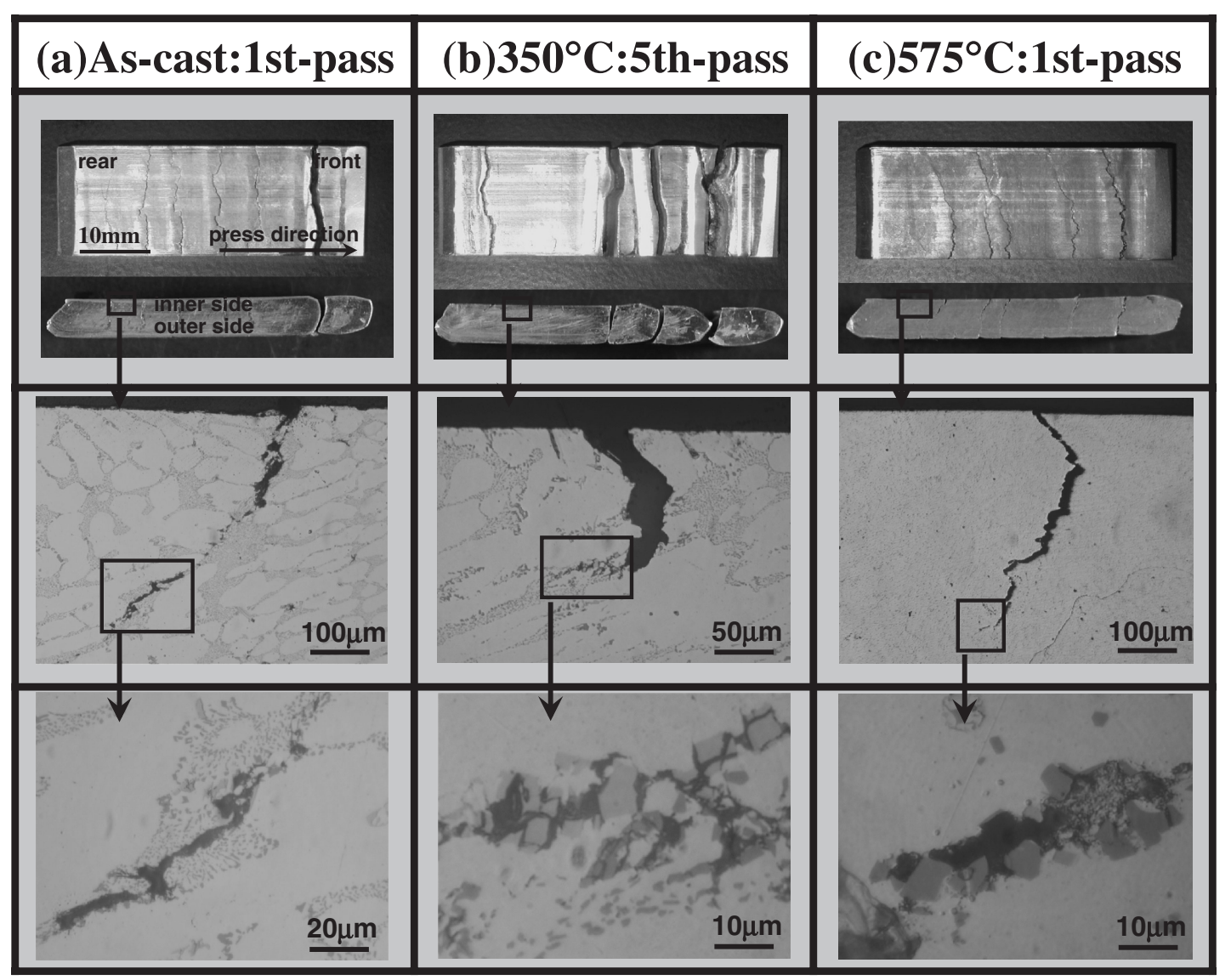

Fig. 11 Optical micrographs showing crack growth path of specimens with or without preheating treatment.

red easily at 1st-pass in ECAP process for both the As-cast specimen and the specimens preheated at below 230 or $575^{\circ} \mathrm{C}$. Microstructural features of the specimen preheated at $350^{\circ} \mathrm{C}$ were characterized by both the fairly decrease in hardness of primary $\alpha-\mathrm{Al}$ and no changes in cross-sectional area and morphology of eutectic Si particles. In addition to the above, when the hardness of the primary $\alpha$-Al reached to a specified value due to a strain hardening by the repetitive ECAP press, the cracks occurred in the test piece and the ECAP process became impossible. These experimental results implied that the hardness of the primary $\alpha$-Al gave a useful indication for the ECAP formability. Cracks at the rear section of the test piece initiated on the inner side of ECAP channel angle and propagated preferentially along the solidification cell regions, that is, not only at the interface between aluminum matrix and eutectic Si particles but also at the transcrystalline cracking of eutectic Si particles.

\section{Acknowledgements}

The authors would like to express their great thanks to Hitachi Metals, ltd. for supplying the materials. A part of the present study was financially supported by The Light Metal Educational Foundation, Inc.

\section{REFERENCES}

1) R. S. Mishra and Z. Y. Ma: Mater. Sci. Eng. R 50 (2005) 1-78.

2) S. Tahara, Y. Kume, M. Kobashi and N. Kanetake: J. Jpn. Soc. Tech. Plas. 50 (2009) 109-113.

3) J. M. Garcia-Infanta, A. P. Zhilyaev, C. M. Cepeda-Jimenez, O. A. Ruano and F. Carreno: Scr. Mater. 58 (2008) 138-141.

4) S. Ashouri, M. Nili-Ahmadabadi, M. Moradi and M. Iranpour: J. Alloy. Compd. 466 (2008) 67-72.

5) P. Szczygiel, H. J. Roven and O. Reiso: Mater. Sci. Eng. A 493 (2008) 202-206.

6) A. Yoshida, H. Tezuka and T. Sato: Proc. 102th Conf, (Jpn. Inst. Light Metals, Sapporo, 2002) pp. 343-344.

7) K. Matsubara, K. Makii and Z. Horita: Proc. 102th Conf, (Jpn. Inst. Light Metals, Sapporo, 2002) pp. 327-328.

8) A. Ma, N. Saito, M. Takagi, Y. Nishida, H. Iwata, K. Suzuki, I. Shigematsu and A. Watazu: Mater. Sci. Eng. A 395 (2005) 70-76.

9) A. Ma, K. Suzuki, N. Saito, Y. Nishida, M. Takagi, I. Shigematsu and H. Iwata: Mater. Sci. Eng. A 399 (2005) 181-189.

10) A. Ma, M. Takagi, N. Saito, H. Iwata, Y. Nishida, K. Suzuki and I. Shigematsu: Mater. Sci. Eng. A 408 (2005) 147-153.

11) A. Ma, K. Suzuki, Y. Nishida, N. Saito, I. Shigematsu, M. Takagi, H. Iwata, A. Watazu and T. Imura: Acta Mater. 53 (2005) 211-220.

12) Z. Horita, M. Furukawa, T. G. Langdon and M. Nemoto: Materia Japan 37 (1998) 767-774.

13) S. J. Oh and S. B. Kang: Mater. Sci. Eng. A 343 (2003) 107-115.

14) K. Matsuda and S. Ikeno: J. Jpn. Inst. Light Met. 50 (2000) 23-36. 